\title{
A importância do tratamento transdisciplinar para lesão cervical não cariosa e hipersensibilidade dental e sua influência na qualidade de vida: relato de caso
}

The importance of transdisciplinary treatment for non-carious cervical lesions and dental

\author{
hypersensitivity and the influence on quality of life: case report \\ La importancia del tratamiento transdisciplinario de las lesiones cervicales no cariosas y la \\ hipersensibilidad dental y su influencia en la calidad de vida: relato de caso
}

Recebido: 19/10/2021 | Revisado: 04/11/2021 | Aceito: 08/11/2021 | Publicado: 13/11/2021

Tadeu Evandro Mendes Junior ORCID: https://orcid.org/0000-0001-7863-3842 Universidade José do Rosário Vellano, Brasil E-mail: tadeu.junior@unifenas.br

Junia Cardoso Pinheiro ORCID: https://orcid.org/0000-0001-7653-8219 Universidade José do Rosário Vellano, Brasil E-mail: juhpinheiro92@gmail.com

Monique Dias Silva

ORCID: https://orcid.org/0000-0001-6544-7928 Universidade José do Rosário Vellano, Brasil

E-mail: monique.dias@aluno.unifenas.br

João Gustavo Rabelo Ribeiro

ORCID: https://orcid.org/0000-0001-3593-6004

Universidade José do Rosário Vellano, Brasil E-mail: joão.ribeiro@unifenas.br

Tadeu Evandro Mendes

ORCID: https://orcid.org/0000-0001-6286-9922

Universidade José do Rosário Vellano, Brasil E-mail: tadeu.junior@unifenas.br

\begin{abstract}
Resumo
Quando se trata de uma patologia no ser humano, devemos neutralizar as áreas de especialidade e abranger o indivíduo como um todo, devolvendo ao indivíduo o bem estar físico, psíquico e social. A hipersensibilidade dental e a lesão cervical não cariosa são patologias que atualmente apresentam grande prevalência mundial na odontologia, que influenciam na qualidade de vida do paciente. Estas patologias apresentam etiologia multifatorial, sendo importante uma análise. O presente artigo tem como objetivo relatar o caso clínico de uma paciente que apresentava sensibilidade dolorosa grau 9 na escala EVA de dor o que influenciava diretamente na qualidade de vida. O tratamento foi baseado no tratamento transdisciplinar, envolvendo várias especialidades da odontologia para solução do tratamento. $O$ resultado foi alcançado, a paciente relatou mudança para grau 0 na escala EVA e pode devolver à paciente uma melhor qualidade de vida.
\end{abstract}

Palavras-chave: Sensibilidade da dentina; Comunicação interdisciplinar; Odontologia.

\begin{abstract}
When there is a human pathology, health professionals should not treat patients by specialty. They must treat patients analyzing all areas and pathologies they may have in a transdisciplinary way, restoring the individual's physical, psychological and social well-being. The dental hypersensitivity and non-carious cervical lesions are pathologies that currently have a great worldwide prevalence in dentistry, which influence the patient's quality of life. These pathologies have a multifactorial etiology, and an analysis is important. This article aims to report the clinical case of a patient who presented pain sensitivity grade 9 on the VAS pain scale, which directly influenced her quality of life. The treatment was based on transdisciplinary treatment, involving several specialties of dentistry to solve the treatment. The result was achieved, the patient reported a change to grade 0 on the VAS scale and can return the patient to a better quality of life.
\end{abstract}

Keywords: Dentin sensitivity; Interdisciplinary communication; Dentistry. 


\section{Resumen}

Cuando existe una patología humana, los profesionales de la salud no deben tratar a los pacientes por especialidad. Deben tratar a los pacientes analizando todos los ámbitos y patologías que puedan tener de forma transdisciplinar, restableciendo el bienestar físico, psicológico y social del individuo. La hipersensibilidad dental y las lesiones cervicales no cariosas son patologías que actualmente tienen una gran prevalencia mundial en odontología, que influyen en la calidad de vida del paciente. Estas patologías tienen una etiología multifactorial y el análisis es importante. Este artículo tiene como objetivo reportar el caso clínico de una paciente que presentó sensibilidad al dolor grado 9 en la escala de dolor EVA, lo que influyó directamente en su calidad de vida. El tratamiento se basó en un tratamiento transdisciplinario, involucrando varias especialidades de la odontología para solucionar el tratamiento. El resultado se logró, el paciente informó un cambio a grado 0 en la escala EVA y puede devolver al paciente a una mejor calidad de vida.

Palabras clave: Sensibilidad dentinaria; Comunicación interdisciplinar; Odontología.

\section{Introdução}

A lesão cervical não cariosa (LCNC) é uma patologia bucal que apresenta perda estrutural dentária a nível cervical, não causado por processo carioso (Absi, Addy \& Adams, 1987). Nas últimas décadas há um aumento significativo na prevalência, afetando um em cada seis indivíduos, igualmente entre homens e mulheres (Addy \& Hunter, 2003).

Um dos principais sintomas da LCNC é a hipersensibilidade dentinária cervical (HDC), que é uma resposta dolorosa dental a um estímulo tátil, térmico, osmótico ou químico ou ainda, pela combinação destes (Aranha, Pimenta \& Marchi, 2009; Bartold, 2006). Isto ocorre devido a teoria da hidrodinâmica presente dentro dos túbulos dentinários que se apresentam expostos ao meio bucal (Grippo, 1991).

A etiologia para a LCNC é complexa e provém de associação ou combinação entre dois ou mais fatores, como: a abrasão, provocada por um desgaste mecânico (Grippo, Simring \& Schreiner, 2004); a erosão é causado pela ação dos ácidos, provenientes de fatores extrínsecos ou intrínsecos (Grippo, Smring \& Coleman, 2012; Kimura, Wilder-Smith, Yonaga \& Matsumoto, 2000; Maltarollo, Pedron, Medeiros, Kubo, Martins \& Shitsuka, 2020) e a abfração, como a perda patológica de tecido duro, devido a forças biomecânicas que causam tensão dental (Lee \& Eakle, 1984). Estes fatores, ainda estão associados à alterações térmicas, hábitos, cultura e fatores socioeconômicos (Grippo et. al, 2004).

Para o cirurgião dentista, além da complexidade no diagnóstico, inúmeros procedimentos técnicos e alternativas terapêuticas transdisciplinares podem ser necessárias para a solução do tratamento para o paciente (Lopes, Eduardo \& Aranha, 2015). O presente artigo tem como objetivo relatar um caso clínico, na qual a paciente apresentava com muita sensibilidade dental no qual interferia diretamente na qualidade de vida.

\section{Metodologia}

Este trabalho trata-se de um estudo de caso clínico descritivo, analítico e qualitativo para fins odontológico (Pereira, Shitsuka, Parreira \& Shitsuka, 2018). O relato do estudo clínico foi previamente aprovado pelo comitê de ética e pesquisa, CAAE: 39448720.9.0000.5143, e parecer número: 4.462.759.

\section{Estudo do Caso}

Paciente gênero feminino, 38 anos de idade, apresentou-se à clínica particular, relatando sintomatologia dolorosa em quase todos os dentes ao ingerir alimentos frios e gelados. No relato ela questiona que a dor estava incomodando ao ponto de não conseguir ter uma vida tradicional, como tomar sorvete com os filhos, beber um vinho, entre outros relatos.

Após o relato da queixa principal, foi realizado a anamnese onde a paciente relatou que usualmente tinha uma dieta rica em alimentos ácidos em suas principais refeições, estresse e dor orofacial. Não apresentava outra patologia sistêmica, como refluxo, doença gástrica, etc. 
Em seguida realizou-se os exames clínicos. A paciente não apresentava nenhuma alteração facial, articular ou ganglionar. No exame intrabucal observou-se a ausência dos dentes no arco superior e inferior (elementos dentários 14, 24 34, 44), com espaços devidamente fechados pelo tratamento ortodôntico, presença de tártaro na região dos incisivos inferiores, relação de molar em Cl II de Angle, com apinhamento superior e inferior anterior leve, curva de Spee alterada, recessão gengival acompanhado de perda estrutural na região cervical dos dentes posteriores superiores e inferiores e o elemento 46 reabilitado por meio de prótese sobre implante (Figura 1).

Figura 1. Fotografia intra bucal inicial. A) Fotografia intra bucal direita. B) Fotografia intra bucal frontal. C) Fotografia intra bucal esquerda. D) Oclusal superior. E) Oclusal inferior

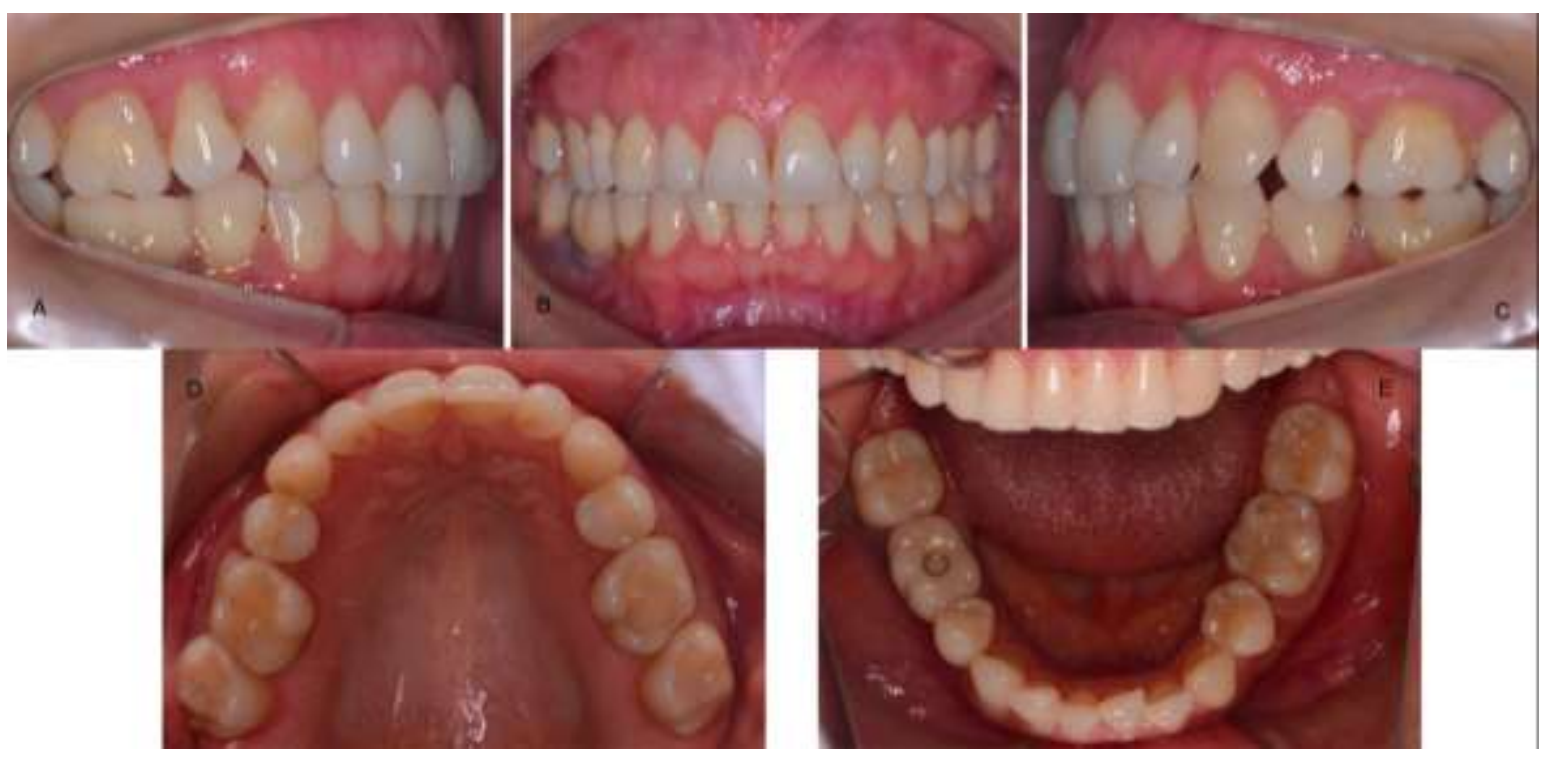

Fonte: Autoria própria.

Durante o exame clínico também foi realizado o teste de sensibilidade dentinária com jatos de ar e água, na qual a paciente apresentou índices elevados de dor, em todos os dentes posteriores superiores e inferiores. Utilizando a escala visual analógica (EVA) a paciente relatou nível 9 de dor.

Para diagnóstico diferencial de outras patologias foi solicitado à paciente radiografias intra e extrabucal como: periapical de todos os dentes, interproximais e panorâmica. Com os laudos e avaliação dos exames foi descartado qualquer patologia dental cariosa ou lesão periapical. 
Figura 2. Exame radiográfico extra bucal, panorâmica inicial.

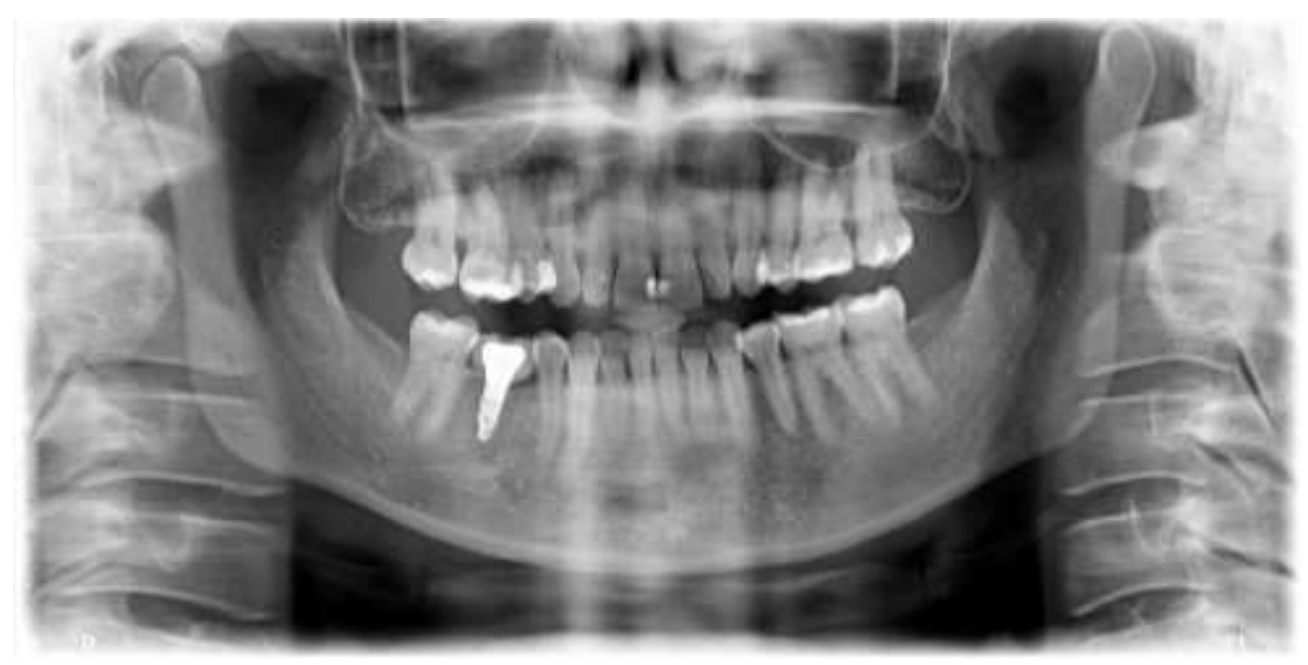

Fonte: Autoria própria.

Pelos sinais e sintomas clínicos e imaginológicos a paciente foi diagnosticada com LCNC. Por ser tratar de uma patologia complexa envolvendo fatores como erosão dentária, abrasão e tensão (Bartold, 2006), inicialmente foi proposto à paciente um tratamento multidisciplinar

A princípio, a paciente foi orientada sobre técnica de higienização bucal do tipo Bass, além da indicação de alguns produtos de higiene bucal como: a escova Colgate Slim Soft (Colgate-Palmolive Comercial Ltda, São Paulo, São Paulo, Brasil), creme dental Colgate sensitive pró-alívio imediato (Colgate-Palmolive Comercial Ltda, São Paulo, São Paulo, Brasil) e fita dental Total 12 (Colgate-Palmolive Comercial Ltda, São Paulo, São Paulo, Brasil). Na mesma consulta, foi explicado o risco que o excesso de alimentação ácida causa ao dente e a importância da tamponação salivar na cavidade bucal. Foi encaminhada ao profissional responsável pela alimentação do paciente uma carta sobre os cuidados e risco do ácido aos dentes.

$\mathrm{Na}$ consulta subsequente foram analisados o fator fricção e atrição, ocasionado pela relação oclusal. Foi realizado a montagem oclusal em articulador semi ajustável para detalhamento da oclusão, desoclusão, toques pré-maturos, bem como detalhamento das lesões cervicais. Inicialmente a paciente foi submetida a moldagem com silicona de adição (Elite HD+ Putty Soft - Zhermack) e gesso tipo IV (Gesso Pedra Especial Durone - Dentsply) para detalhamento dos dentes e principalmente da região da lesão cervical, em seguida foi confeccionada um JIG de Lucia para desprogramação oclusal. Após desprogramação foi registrado a oclusão, por meio do Oclusofast (Registro Oclusal Occlufast Rock - Zhermack) em relação cêntrica e também foi realizado as medidas craniométricas o oclusais com o arco facial (Bio-Art equipamentos odontológicos ltda, São Carlos, São Paulo, Brasil). Com os registros foi montado em articulador semi-ajustável A7 Fix (Bio-Art equipamentos odontológicos ltda, São Carlos, São Paulo, Brasil).

Com os registros pode analisar com maior precisão os contatos indesejados em relação cêntrica bem como as funções de lateralidade e protrusão. Observou-se contatos prematuros na região dos $1^{\circ} \mathrm{s}$ pré molares superiores e inferiores que levavam a anteriorização da mandíbula em máxima intercuspidação habitual, além disso durante a lateralidade os movimentos aconteciam nos dentes posteriores e com toques indevidos do lado de balanceio.

Como a relação oclusão não estava favorável e a paciente apresentava apinhamento anterior, interferindo na estética dental, a princípio foi proposto tratamento ortodôntico para solução da oclusão. Porém a paciente não aceitou a proposta.

Por causa da recusa do paciente no tratamento ortodôntico e com os modelos montados em articulador, foi realizado um desgaste seletivo prévio no modelo de gesso para analisar se o desgaste seletivo poderia ser um tratamento sem comprometer 
o esmalte e a integridade dental. E foi possível, com isso reproduzimos os mesmos desgastes no dente da paciente e conseguimos devolver a guia de desoclusão anterior e guia canina.

Com fatores etiológicos controlados, as próximas etapas foram a eliminação da sintomatologia dolorosa, no qual foi previamente tratado por meio químicos de despolarização neural. Para obliteração dos túbulos dentinários onde apresenta os prolongamentos odontoblásticos foi proposto dois métodos. Os dentes que apresentavam LCNC foi proposto restauração classe V para melhora primária da HDC e como secundária a estética dental. Os dentes que não apresentavam LCNC, porém apresentavam HDC, foi proposto a obliteração dos túbulos dentinários por meio da vedação hermética.

Para a terapia obliteradora, foi utilizado o obliterador dentinário químico Gluma desensitizer (Kulzer GmbH, Leipziger, Germany). Previamente a aplicação, foi controlado a umidade por meio do afastamento labial, isolamento relativo com roletes de algodão e do fio retrator \#000 (Ultradent, Indaiatuba, SP, Brasil) dentro das limitações de profundidade do sulco gengival. Uma quantidade mínima do produto foi aplicada sobre a superfície de dentina com tempo de espera de 60 segundos. Em seguida, foi utilizado o jato de água para enxaguar a superfície abundantemente. O procedimento foi repetido por 2 dias. Na terceira sessão, após 2 dias, os procedimentos de isolamento relativo com algodão e afastamento labial foram realizados, e em seguida um agente à base de fosfato de cálcio nanoestruturado, com flúor e nitrato de potássio, foi inserido na superfície dentinária exposta com o auxílio de um microaplicador. Imediatamente após sua aplicação, o produto foi friccionado durante 10 segundos, com taça de borracha ou disco de feltro, e removido após 5 minutos, com rolete de algodão seco. Foi orientado quanto à não ingestão de alimentos sólidos ou líquidos por pelo menos 30 minutos após o procedimento. O mesmo protocolo de aplicação foi realizado por mais uma vez, após um intervalo de 2 dias.

Nos dentes que apresentavam uma perda significativa de estrutura dental, foi realizada a restauração da lesão cervical não cariosa com resina composta em sessões de hemiarco. Inicialmente a paciente foi submetida a anestesia de bloqueio alveolar e realizou-se uma profilaxia com Consepsis Scrub (Ultradent Products Inc., South Jordan, UT, USA). Em seguida, controlou-se a umidade por meio de isolamento absoluto com grampos afastadores de sulco gengival.

Após o procedimento de isolamento e profilaxia, preconizamos o condicionamento com ácido fosfórico 37\% (Condac, FGM, Joinville - SC Brasil) por 15 segundos apenas em esmalte. Após lavar abundantemente com água por um período de 30 segundos, o controle da umidade foi realizado com papel absorvente. Em seguida, aplicou-se o sistema adesivo universal (Ambar, FGM, Joinville - SC Brasil) esfregando-o contra a estrutura dental por 10 segundos, uma nova camada foi aplicada por mais 10 segundos. Uma sessão de jato de ar foi aplicada por 10 segundos para evaporação do solvente, conforme preconizado pelo fabricante. Como último passo houve a fotopolimerização (Valo,Ultradent, Salt Lake City, Utah, EUA) por 10 segundos.

Com a aplicação do adesivo, os dentes foram restaurados com dois incrementos. O primeiro na região profunda da cavidade, parede axial, foi realizado com resina composta Charisma da cor OA3 (Heraeus- Kulzer, Hanau, Alemanha), e fotopolimerização (Valo,Ultradent, Salt Lake City, Utah, EUA) por 20 segundos. Na camada superficial foi utilizado a resina Charisma da cor A3 (Heraeus- Kulzer, Hanau, Alemanha) e novamente fotopolimerizado por 20 segundos, conforme o fabricante preconiza. Em seguida era aplicado o gel bloqueador de oxigênio (PoweBlock - BM4). Após a confecção foi removido o isolamento absoluto e realizado o acabamento prévio da região cervical com lâmina de bisturi 12. No dia seguinte foi realizado o polimento da restauração com a utilização de polidores espirais com granulações diferentes (Sof-lex Discos espirais - 3M).

Uma nova mensuração da dor foi realizada após 15 dias, para que fizéssemos a comparação da intensidade de dor, utilizando a mesma escala visual de avaliação (EVA) para fins de comparação. Após o teste de ar e água de HD, a paciente não relatou nenhum incômodo, acurado a intensidade 0 na escala. Com isso podemos afirmar concluindo o caso clínico de forma satisfatória (Figura 3). 


\section{Discussão}

A dor dental pode estar relacionada a inúmeras patologias bucais (Machado, Zeola \& Wobido, 2019; Soares \& Grippo, 2017). É importante o cirurgião-dentista organizar as informações presentes na anamnese, e junto com o exame clínico, planejar as hipóteses de diagnóstico. Tendo a possibilidade de mais de um diagnóstico ele deve solicitar o paciente exames complementares, no qual direciona ao diagnóstico mais preciso a respeito da patologia presente.

Uma alternativa de exame complementar para diagnóstico diferencial para os pacientes com HDC é por estímulo mecânico, térmico ou osmótico na região onde o paciente acusa apresentar hipersensibilidade dentinária. O teste é realizado por meio de aplicação osmótica de jato de ar por um período de 2 segundos a uma distância de $1 \mathrm{~cm}$ da região, apenas na região cervical com suspeita de dor (Soares \& Grippo, 2017). As estruturas adjacentes a região com sensibilidade deve estar vedada com algodão para não ca5usar erro de diagnóstico confundidas com lesão cariosa na região interproximal (Soares \& Grippo, 2017).

Figura 3. Fotografia intra oral inicial e final, observa-se as restaurações na região cervical,vedando a dentina exposta e diminuindo a sensibilidade. A) Fotografia inicial lateral direita. B) Fotografia inicial frontal. C) Fotografia inicial lateral esquerda D) Fotografia final direita. E) Fotografia final frontal. F) Fotografia final lateral esquerda.
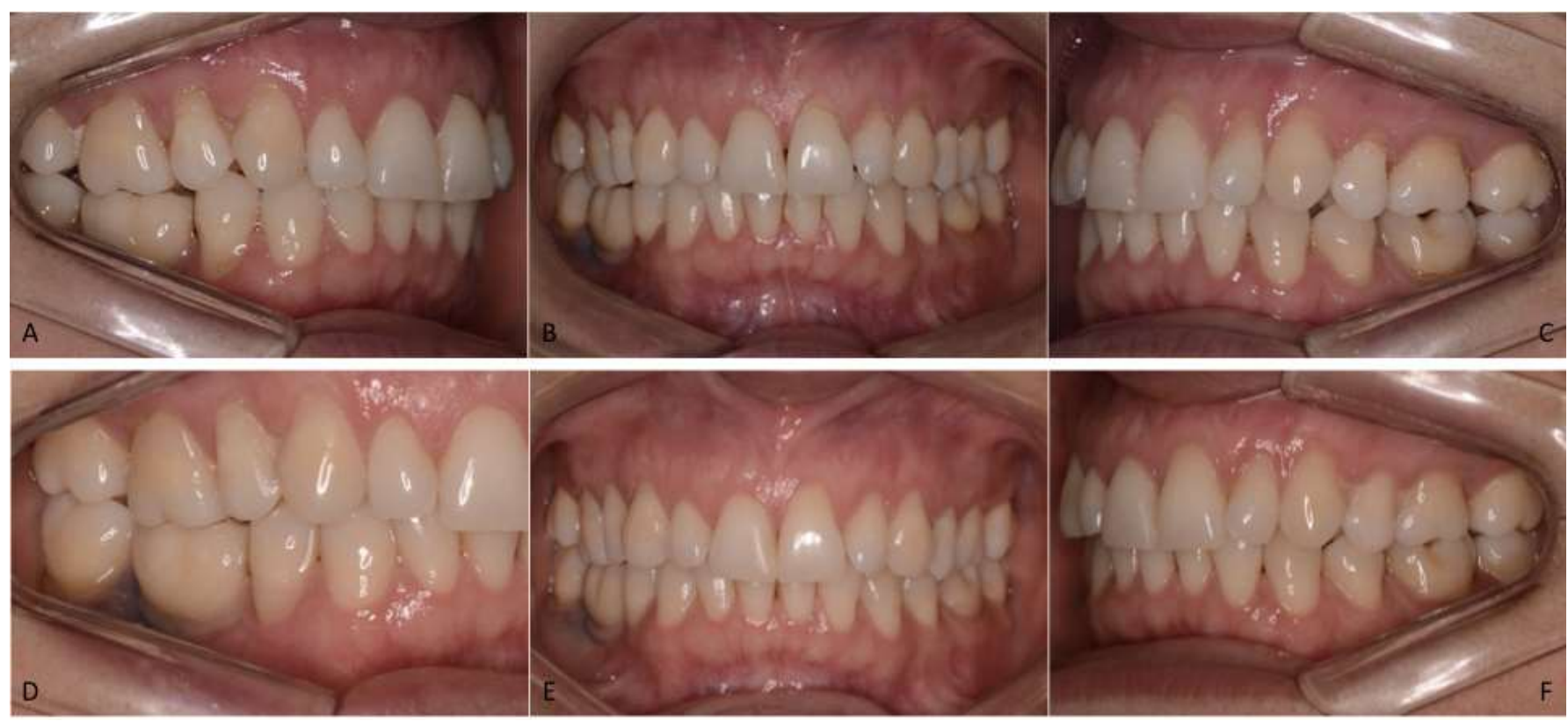

Fonte: Autoria própria.

A sensação dolorosa é subjetiva, por isso a dor não pode ser determinada por instrumentos físicos (Soares \& Grippo, 2019). Para mensuração da intensidade de dor é usado um método conhecido como EVA (Escala Visual Analógica), pois ela apresenta como vantagem ser de fácil utilização e eficaz (Gondim, 2011). A quantificação da dor é extremamente importante para estes pacientes, pois apresenta parâmetros para podermos analisar o objetivo do tratamento da hipersensibilidade (Gondim, 2011).

A busca pela etiologia patológica é um fator primordial em qualquer tratamento. A oclusão é importante para o tratamento da patologia LCNC e HDC. As interferências oclusais não concentradas ao longo eixo dental podem gerar intercorrências patológicas irreversíveis na estrutura dental, devido à flexão provocada durantes os movimentos de oclusão e desoclusão, sendo a região cérvico-gengival mais propício a acontecer a perda de tecidos duros (esmalte e dentina) (Soares \& 
Grippo, 2017). Além de provocar a perda estrutural diretamente, ela influencia no tratamento das restaurações classe V. Pela anatomia estrutural da restauração, formato de "V", se não for eliminado esse fator a deflexão promovida da estrutura dental, pode facilitar a expulsão da resina presente na região (Soares \& Grippo, 2017).

No caso clínico relatado, a paciente não apresentava uma oclusão satisfatória. O canino superior não se apresenta em relação distal ao canino inferior, consequentemente a guia lateral de desoclusão ficava comprometida. Durante os movimentos de desoclusão lateral os dentes que sofreram carga eram os 1o pré molares. Estes mesmos apresentavam maior perda estrutural. Além disso, os pré molares encontram-se em um sítio no qual apresenta-se com menor quantidade óssea na região vestibular, ocasionando menor chance de recessão gengival, exposição radicular, bem como perda estrutural e hipersensibilidade dentinária (Soares \& Grippo, 2017).

Além da desoclusão lateral ser realizado nos pré molares, o primeiro contato oclusal em relação cêntrica era realizado neste mesmo dente e em seguida a mandíbula era levemente anteriorizada para relação de máxima intercuspidação habitual (MIH). Esta relação pode desenvolver algumas parafunções relacionadas a outras patologias extra bucais, como o estresse. Essa situação (má oclusão e estresse), pode desenvolver parafunção o que poderá ocorrer forças de flexão que agem sobre o dente, causando a ruptura das ligações químicas de hidroxiapatita do esmalte na região cervical. À medida que essas ligações vão sendo partidas, moléculas de água ou substâncias orgânicas penetram nessas "fendas", impedindo uma nova união química entre os cristais. Isso favorece o esmalte a sofrer dissolução química proveniente de ácidos de origem extrínseca e intrínseca e ao desgaste mecânico abrasivo que pode ser gerado pela escovação incorreta (Soares \& Grippo, 2017).

A montagem em articulador semi ajustável dá a possibilidade de diagnóstico da oclusão em relação cêntrica, bem como a desoclusão. É convicto na odontologia, a preferência sempre por tratamento reversível. Qualquer hipótese de tratamento irreversível deve ser tomada mediante da certeza sobre a hipótese diagnóstico. No caso relatado, a hipótese de tratamento ortodôntico seria benéfica a paciente no sentido de preservação da estrutura dental, bem como na estética. A rejeição da paciente por ser um tratamento complexo e envolver alguns anos descartou a possibilidade de tratamento reversível de perda de esmalte. Os modelos de gesso montados em articulador semi ajustados possibilitou a simulação da quantidade de esmalte que seria desgastado para conseguirmos evitar os contatos oclusais insatisfatórios. Foram realizados os desgastes no gesso e analisados se a quantidade desgastada interferiria na exposição dentinária. Com resultado obtido, foi possível a reprodução do desgaste dental sem exposição dentária.

$\mathrm{O}$ tratamento de pacientes com LCNC e HDC é complexo e envolve várias etapas, como mencionado anteriormente. Nas primeiras sessões do paciente, deve-se remover os fatores etiológicos da patologia a fim de obter sucesso no tratamento. Por isso, e como relatado no caso clínico, indicamos o creme dental para sensibilidade, com o objetivo de diminuir a sensação dolorosa e dar uma qualidade de vida melhor ao paciente até que seja removido a etiologia, bem como, a obliteração dos túbulos dentinário (Soares \& Grippo, 2019).

Um creme dental deve apresentar como características a viscosidade, citotoxicidade e quantidade ideal de cálcio e flúor. A viscosidade contribui para facilitar o fluxo da pasta de dente no tubo e facilitar a aplicação do creme na escova. Um creme dental não pode ser tóxico, e sua toxicidade é medida pelo RDA (radioative dentin abrasion), que está diretamente relacionado com o grau de desgaste dental, pois superfícies erodidas podem ser facilmente desgastadas se forem escovadas por dentifrícios altamente erosivos. Quanto maior a quantidade de cálcio e flúor o creme dental tiver disponível maior a capacidade de remineralização do dentifrício. $\mathrm{O}$ íon fluoreto age principalmente pela formação de precipitados de fluoreto de cálcio (Caf2) na superfície dentinária, que serve como depósito de flúor que são liberados quando há uma alteração no pH, protegendo contra desmineralização ou atuando na remineralização (Gatona, 2018).

No mercado odontológico atual existem inúmeros materiais e mecanismos de atuação na obliteração dos túbulos dentinários. O cirurgião-dentista deve avaliar as possibilidades e limitações de cada material para o caso clínico presente, 
objetivando a personalização do tratamento. $\mathrm{O}$ uso de mecanismo obliterador tem por função impedir a micro movimentação dos fluidos dentinários por meio da obliteração dos túbulos expostos ao meio oral, evitando a estimulação dos barorreceptores e consequentemente propagação da dor. Os dessensibilizantes obliteradores químicos são classificados de acordo com a sua ação, e agem como precipitantes de proteína, dentre eles os mais usados são: glutaraldeído, nitrato de prata, cloreto de estrôncio. Os precipitantes de cristais são classificados em derivados de cálcio, fluoreto de sódio, oxalatos, vernizes e também podem auxiliar na terapia obliteradora (Soares \& Grippo, 2017).

Os dentes que apresentavam perda estrutural aparente foram reconstruídos com materiais restauradores a base de resina composta. Estes materiais, além da indicação estética, reduzem a hipersensibilidade dentinária por meio da obliteração mecânica dos túbulos dentinários, bem como, promove uma homogeneização do desequilíbrio do comportamento biomecânico da função mastigatória (Gatona, 2018).

Como em qualquer restauração dentária, etapas pré definidas de competência técnica devem ser respeitadas e executadas de forma correta para o sucesso do procedimento. Durante a restauração com resina composta híbrida de modo direto, um fator crítico é a dificuldade de isolamento absoluto do campo operatório. A região cervical é um local com grande umidade, desfavorecendo a união entre material restaurador e estrutura dental em função do componente hidrofílico presente na estrutura adesiva. Se não bem controlada, ocorrem falhas e maior risco de insucesso no tratamento (Santiago, Passos, Vieira, Navarro, Lauris \& Franco, 2010).

Não há consenso sobre o melhor método de aplicação do condicionamento ácido e do adesivo para restauraçães (Kumagai, Hirata, Pereira \& Reis, 2020). Um dos fatores críticos para o sucesso é a inserção de incrementos de resina composta. A grande quantidade de incremento durante a restauração na busca por adequação ótica na região, pode causar aumento na contração do material ocasionando falhas. Além disso, aumento considerável no tempo clínico, ocasionando em maior chance de não controle da umidade. Uma alternativa é a utilização de resina composta do tipo Bulk-fill. Ela apresenta uma alternativa viável uma vez que apresenta um comportamento biomecânico favorável e apresenta melhor tempo clínico, pois necessita de apenas 1 incremento (Correia, Andrade, Tribst, Borges \& Caneppele, 2020).

Os diversos componentes presentes na resina composta é um fator que deve ser analisado durante a restauração classe V. Compósitos microparticulados apresentam menor módulo elástico, comparados ao micro híbridos, o que confere uma maior flexão na interface adesiva, reduzindo as falhas nas restaurações (Namgung, Rho, Jin, Lim \& Cho, 2013).

Conclui-se que o diagnóstico e plano de tratamento para pacientes com LCNC e com HDC deve ser individualizado, inúmeros fatores podem ocasionar o sucesso ou a falha no tratamento. Análise detalhada durante a anamnese, dados de histórico médico, exame clínicos e complementares determinarão o diagnóstico do paciente e várias etapas clínicas são fundamentais para o sucesso do tratamento.

Através do relato do caso clínico podemos constatar que as lesões cervicais não cariosas apresentam diagnóstico complexo e decorrem da associação de mais de um fator etiológico ocasionando a perda irreversível de estrutura dental. Para o tratamento das lesões não cariosas, é indispensável identificação e remoção do fator causal, antes de instituir o tratamento, seja este restaurador ou não. As LCNC exigem um amplo e complexo diagnóstico, e têm se tornado um problema de saúde pública e necessitam de maior divulgação tanto para a população leiga quanto para a capacitação dos profissionais.

\section{Conclusão}

As lesões cervicais não cariosas apresentam diagnóstico complexo e decorrem da associação de mais de um fator etiológico ocasionando a perda irreversível de estrutura dental. Para o tratamento das lesões não cariosas, é indispensável identificação e remoção do fator causal. As LCNC exigem um amplo e complexo diagnóstico, e têm se tornado um problema de saúde pública, necessitando de maior divulgação tanto para a população leiga quanto para a capacitação dos profissionais. . 


\section{Agradecimentos}

Agradecimento especial à paciente. A coordenação da Universidade e todo os professores por contribuir com este artigo.

\section{Referências}

Absi, E. G, Addy, M \& Adams, D. (1987). Dentine Hypersensitivity. A study of the patency of dentinal tubules in sensitive and non-sensitive cervical dentine. Journal Clinical Periodontology, 14(5), 280-284.

Addy, M \& Hunter, M. L. (2003). Can Tooth brushing damage your health? Effects on oral and dental tissues. International Dental Journal, 53 , $177-186$.

Aranha, A. C, Pimenta, L. A \& Marchi, G. M. (2009) Clinical evaluation of desensitizing treatments of cervical dentin hypersensitivity. Brazilian Oral Research, 23(3), 333-339.

Bartold, P. M. (2006). Dentinal Hypersensitivity: a review. Australian Dental Journal, 51(3), 212-218.

Correia, A, Andrade, M. R, Tribst, J, Borges, A \& Caneppele, T. (2020) Influence of Bulk-fill Restoration on Polymerization Shrinkage Stress and Marginal Gap Formation in Class V Restorations. Operative Dentistry, 45(4), 207-216.

Gatona, R. M. L. (2018). Hipersensibilidade dentinária e desgaste dental: abordagem epidemiológica, sobre auto-percepção e conhecimento, caracterização física e biológica e estudo in situ do desgaste e oclusão tubular de cremes dentais dessensibilizantes elou anti erosivos. Tese (Doutorado) Faculdade de Odontologia da Universidade de São Paulo. São Paulo, SP.

Gondim, R. C. D. (2011) Hipersensibilidade dentinária de lesões cervicais não cariosas: abordagens terapêuticas no controle da dor. Revista de Pesquisa em Saúde, 1(12), 52-55.

Grippo, J. O. (1991). Abrifractions: A new classification of hard tissue lesions of teeth. Journal of Esthetic and Restorative Dentistry, 3(1), 14-19.

Grippo, J. O, Simring, M \& Schreiner, S. (2004). Attrition, abrasion, erosion and abfraction revisited: a new perspective on tooth surface lesions. The Journal of the American Dental Association, 135(8), 1109-1118.

Grippo, J. O, Smring, M \& Coleman, T. A. (2012). Abfraction, abrasion, biocorrosion, and the enigma of noncarious cervical lesions: 20-year perspective. Journal Esthetic and Restorative Dentistry, 24(1),10-23.

Kimura, Y, Wilder-Smith, P, Yonaga, K \& Matsumoto, K. (2000). Treatment of dentine hypersensitivity by lasers: a review. Journal of Clinical Periodontology, 27(10), 715-721.

Kumagai, R.Y, Hirata, R, Pereira, P. N. R \& Reis, A. F. (2020). Moist vs over-dried etched dentin: FE-SEM/TEM and bond strength evaluation of resin-dentin interfaces produced by universal adhesives. Journal of Esthetic and Restorative Dentistry, 32(3), 325-332.

Lee. W. C \& Eakle, W. S. (1984). Possible role of tensile stress in the etiology of cervical erosive lesions of teeth. Journal of Prosthetic Dentistry, 52(3), 374380 .

Lopes, A. O, Eduardo, C. P \& Aranha, A. C. (2015). Clinical Evaluation of low power laser and a desensitizing agent on dentin hypersensitivity. Lasers in Medical Science, 30(2), 823-829.

Machado, A. C, Zeola, L. F. \& Wobido, A. R. (2019). Hipersensibilidade dentinaria cervical - etiologia e tratamento. In: Duarte DA, Feres M, Zanatta R. (eds.) Lesões nao cariosas e HMI. Napoleao: Quintessence.

Maltarollo, T. H, Pedron, I. G, Medeiros, J. M. F, Kubo H, Martins, J. L \& Shitsuka, C. (2020). A erosão dentária é um problema! Research, Society and Development, 9(3). 1-10.

Namgung, C, Rho, Y. J, Jin, B. H, Lim, B.S \& Cho, B.H. (2013). A restrospective clinical study of cervical restorations: Longevity and failure prognostic variables. Operative Dentistry, 38, 285-376.

Pereira, A. S, Shitsuka, D. M, Parreira, F. J \& Shitsuka, R. (2018). Metodologia da pesquisa científica. [recurso eletrônico]. Santa Maria, RS. Editora UAB/NTE/UFSM.

Santiago, S. L, Passos, V. F, Vieira, A. H. M, Navarro, M. F, Lauris, J. R \& Franco, E. B. (2010). Two years clinical evalution of resinous restorative systems in non carious cervical lesions. Brazilian Dental Journal, 21, 229-234.

Soares, P. V \& Grippo, J. O. (2017). Lesões cervicais não cariosas e hipersensibilidade dentinária cervical: etiologia, diagnóstico e tratamento. Napoleão: Quintessence Editora; 2017.

Soares, P. V \& Grippo, J. (2019). Hipersensibilidade Dentinária-Guia clínico. Quintessence Editora. 